\title{
BMJ
}

\section{Association of alcohol consumption with selected cardiovascular disease outcomes: a systematic review and meta-analysis}

\author{
Paul E Ronksley, doctoral student, ${ }^{1}$ Susan E Brien, post-doctoral fellow, ${ }^{1}$ Barbara J Turner, professor of \\ medicine and director, ${ }^{2}$ Kenneth J Mukamal, associate professor of medicine, ${ }^{3}$ William A Ghali, scientific \\ director and professor ${ }^{1,4}$
}

\begin{abstract}
${ }^{1}$ Calgary Institute for Population and Public Health, Department of Community Health Sciences,

Faculty of Medicine, University of Calgary, Alberta, Canada T2N 4Z6

${ }^{2}$ REACH Center, University of Texas Health Science Center, San Antonio, TX, USA, and Health Outcomes Research, University Health System, San Antonio

${ }^{3}$ Harvard Medical School and Associate in Medicine, Division of General Medicine and Primary Care, Beth Israel Deaconess Medical Center, Boston, MA, USA

${ }^{4}$ Department of Medicine, Faculty of Medicine, University of Calgary Correspondence to: W Ghali wghali@ucalgary.ca
\end{abstract}

Cite this as: $B M J$ J 2011;342:d671 doi:10.1136/bmi.d671

\section{ABSTRACT}

Objective To conduct a comprehensive systematic review and meta-analysis of studies assessing the effect of alcohol consumption on multiple cardiovascular outcomes.

Design Systematic review and meta-analysis.

Data sources A search of Medline (1950 through

September 2009) and Embase (1980 through September 2009) supplemented by manual searches of

bibliographies and conference proceedings.

Inclusion criteria Prospective cohort studies on the association between alcohol consumption and overall mortality from cardiovascular disease, incidence of and mortality from coronary heart disease, and incidence of and mortality from stroke.

Studies reviewed of 4235 studies reviewed for eligibility, quality, and data extraction, 84 were included in the final analysis.

Results The pooled adjusted relative risks for alcohol drinkers relative to non-drinkers in random effects models for the outcomes of interest were 0.75 ( $95 \%$ confidence interval 0.70 to 0.80 ) for cardiovascular disease mortality (21 studies), 0.71 ( 0.66 to 0.77 ) for incident coronary heart disease ( 29 studies), 0.75 (0.68 to 0.81 ) for coronary heart disease mortality (31 studies), 0.98 (0.91 to 1.06 ) for incident stroke (17 studies), and 1.06 (0.91 to 1.23) for stroke mortality (10 studies). Dose-response analysis revealed that the lowest risk of coronary heart disease mortality occurred with 1-2 drinks a day, but for stroke mortality it occurred with $\leq 1$ drink per day. Secondary analysis of mortality from all causes showed lower risk for drinkers compared with non-drinkers (relative risk 0.87 (0.83 to 0.92$)$ ).

Conclusions Light to moderate alcohol consumption is associated with a reduced risk of multiple cardiovascular outcomes.

\section{INTRODUCTION}

Possible cardioprotective effects of alcohol consumption seen in observational studies continue to be hotly debated in the medical literature and popular media. In the absence of clinical trials, clinicians must interpret these data when answering patients' questions about taking alcohol to reduce their risk of cardiovascular disease. Systematic reviews and meta-analyses have addressed the association of alcohol consumption with cardiovascular disease outcomes ${ }^{1-8}$ but have not uniformly addressed associations between alcohol use and mortality from cardiovascular disease, as well as the incidence and mortality from coronary heart disease and stroke. Additionally, further studies have been published since 2006, when the most recent reviews appeared. The continuing debate on this subject warrants an in depth reassessment of the evidence.

In this paper, we synthesise results from longitudinal cohort studies comparing alcohol drinkers with nondrinkers for the outcomes of overall mortality from cardiovascular disease, incident coronary heart disease, mortality from coronary heart disease, incident stroke, and mortality from stroke. Because of the many biological effects of alcohol consumption, we also examine the association of alcohol with mortality from all causes when this is reported in studies. We conducted meta-analyses for each of these outcomes and a sensitivity analysis with lifetime abstainers as the reference category to account for the heterogeneity within the reference group of non-drinkers. We also examined the effect of confounding on the strength of observed associations. In our companion paper, ${ }^{110}$ we link these cardiovascular outcomes with experimental trials of alcohol consumption on candidate causal molecular markers.

\section{METHODS}

Data sources and searches

We performed a systematic review and meta-analysis following a predetermined protocol in accordance with the Meta-analysis of Observational Studies in Epidemiology (MOOSE) reporting guidelines. ${ }^{9}$ We identified all potentially relevant articles regardless of language by searching Medline (1950 through September 2009) and Embase (1980 through September 


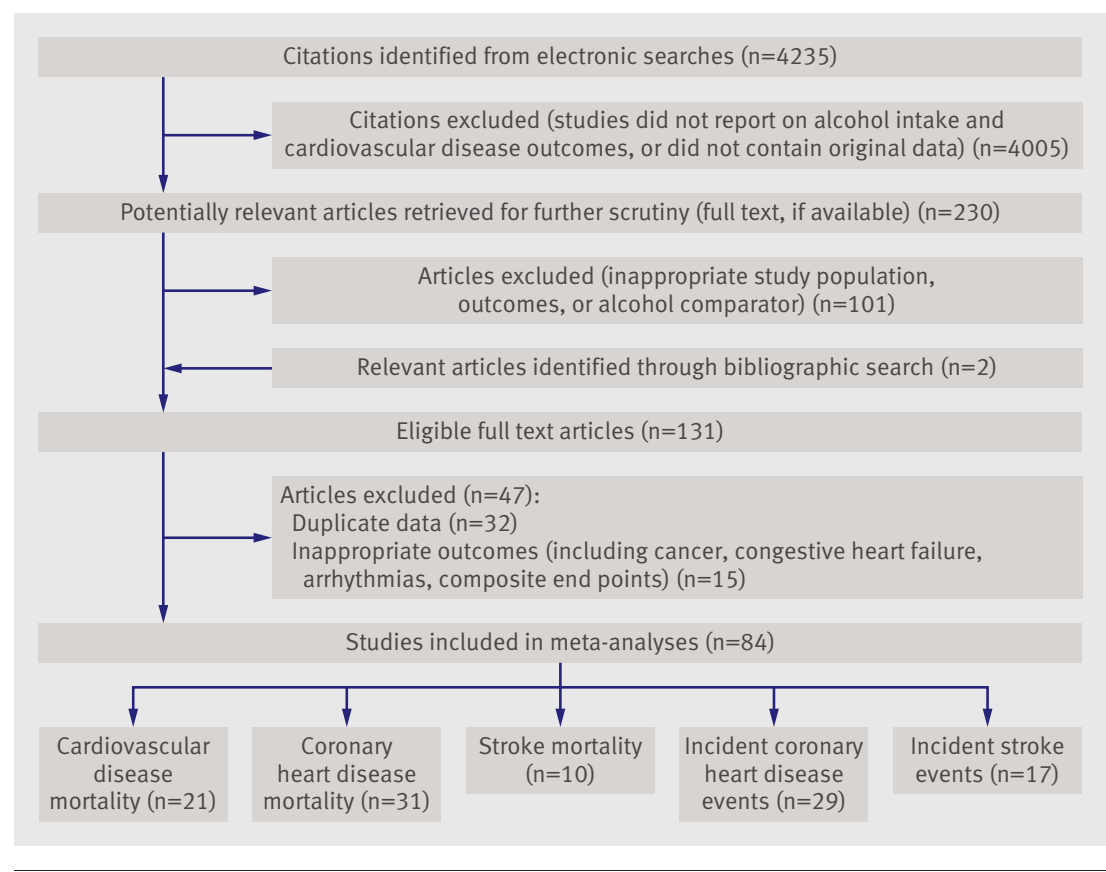

Fig 1| Details of study selection for review

2009). Searches were enhanced by scanning bibliographies of identified articles and review articles, as well as reviewing conference proceedings from three major scientific meetings (American Heart Association, American College of Cardiology, and European Heart Congress) between 2007 and 2009. Experts in the field were contacted regarding missed, ongoing, or unpublished studies.

To search electronic databases, we used the strategy recommended for systematic reviews of observational studies. ${ }^{10}$ We specified three comprehensive search themes:

- To identify relevant terms related to the exposure of interest (theme 1), the first Boolean search used the term "or" to explode (search by subject heading) and map (search by keyword) the medical subject headings "ethanol" or "alcohol" or "alcoholic beverages" or "drinking behaviour" or "alcohol drinking" or text words "drink\$" or "liquor\$" or "ethanol intake" or "alcohol\$ drink\$" or "ethanol drink\$"

- To identify relevant outcomes (theme 2), a second Boolean search was performed using the term "or" to explode and map the medical subject headings "stroke" or "cardiovascular diseases" or "myocardial infarction" or "myocardial ischemia" or "coronary artery disease" or "heart infarction" or text words "cva\$" or "infarct\$" or "ischem\$" or "cvd" or "ami" or "ihd" or "cad"

- To identify relevant study designs (theme 3), a final Boolean search using the term "or" to explode and map the medical subject headings "cohort studies" or "follow-up studies" or "incidence" or "prognosis" or "early diagnosis" or "survival analysis" or text words "course" or predict\$" or "prognos\$" was performed.

These three comprehensive search themes were then combined using the Boolean operator "and" in varying combinations.

\section{Study selection}

Two individuals (SEB and PER) independently reviewed all identified abstracts for eligibility. All abstracts reporting on the association between alcohol intake and cardiovascular disease events were selected for full text review. This stage was intentionally liberal. We discarded only those abstracts that clearly did not meet the aforementioned criteria. The inter-rater agreement for this review was high $(\kappa=0.86$ (95\% confidence interval 0.80 to 0.91$)$ ). Disagreements were resolved by consensus.

The same reviewers performed the full text review of articles that met the inclusion criteria and articles with uncertain eligibility. Articles were retained if they met the inclusion criteria for study design (prospective cohort design), study population (adults $\geq 18$ years old without pre-existing cardiovascular disease), exposure (current alcohol use with a comparison group of nondrinkers), and outcome (overall cardiovascular disease mortality or atherothrombotic conditions, specifically incident coronary heart disease, coronary heart disease mortality, incident stroke, or stroke mortality). Both published and unpublished studies were eligible for inclusion. Authors were contacted if the risk profile of the cohort was unclear.

\section{Data extraction and quality assessment}

The primary exposure variable was the presence of active alcohol drinking at baseline compared with a reference group of non-drinkers. Because of the heterogeneity of this reference group, we identified the subset of studies using lifetime abstainers as the reference group and studies that distinguished former drinkers from nondrinkers. Whenever available, we extracted information on amount of alcohol consumed, using grams of alcohol per day as the common unit of measure. When a study did not specifically report the grams of alcohol per unit, we used $12.5 \mathrm{~g} /$ drink for analysis. ${ }^{11}$ We standardised portions as a $12 \mathrm{oz}(355 \mathrm{ml})$ bottle or can of beer, a $5 \mathrm{oz}$ $(148 \mathrm{ml})$ glass of wine, and $1.5 \mathrm{oz}(44 \mathrm{ml})$ glass of 80 proof ( $40 \%$ alcohol) distilled spirits. Volume of intake was categorised as $<2.5 \mathrm{~g} /$ day $(<0.5$ drink), $2.5-14.9 \mathrm{~g} /$ day (about 0.5-1 drink), 15-29.9 g/day (about 1-2.5 drinks), 30-60 g/day (about 2.5-5 drinks), and $>60 \mathrm{~g} /$ day ( $\geq 5$ drinks).

The outcome variables of interest were defined as the presence or absence of death from cardiovascular disease (that is, fatal cardiovascular or stroke events), incident coronary heart disease (fatal or non-fatal incident myocardial infarction, angina, ischaemic heart disease, or coronary revascularisation), death from coronary heart disease (fatal myocardial infarction or ischaemic heart disease), incident stroke (ischaemic or haemorrhagic events), or death from stroke. A secondary analysis was performed within these selected 
Table 1|Details of studies included in meta-analysis of association of alcohol consumption with selected cardiovascular disease outcomes

\begin{tabular}{|c|c|c|c|c|c|c|c|}
\hline Study & Cohort designation & $\begin{array}{l}\text { No of } \\
\text { subjects }\end{array}$ & Country & Men (\%) & $\begin{array}{c}\text { Age } \\
\text { range } \\
\text { (years) }\end{array}$ & $\begin{array}{c}\text { Study } \\
\text { follow-up } \\
\text { (years) }\end{array}$ & Outcomes measured \\
\hline Albert et al $1999^{22}$ & Physicians' Health Study & 21537 & USA & 100 & $40-84$ & 12 & CHD mortality \\
\hline Bazzano et al $2007^{23}$ & \multirow{2}{*}{$\begin{array}{l}\text { China National Hypertension Survey } \\
\text { Epidemiology Follow-up Study }\end{array}$} & 64338 & China & 100 & $\geq 40$ & 8 & Incident stroke and stroke mortality \\
\hline Bazzano et al $2009^{24}$ & & 64597 & China & 100 & $\geq 40$ & 8 & Incident CHD; CVD and CHD mortality \\
\hline Berberian et al $1994^{25}$ & Zoetermeer Cohort & 1620 & Netherlands & 46.9 & 120 & 10 & CVD mortality \\
\hline Berger et al $1999^{26}$ & Physicians' Health Study & 22071 & USA & 100 & $40-84$ & 12.2 & Incident stroke \\
\hline Blackwelder et al $1980^{27}$ & Honolulu Heart Program & 7888 & USA & 100 & $\begin{array}{l}\text { Not } \\
\text { reported }\end{array}$ & 8 & CHD and stroke mortality \\
\hline Boffetta et al $1990^{28}$ & American Cancer Society Prospective Study & 276802 & USA & 100 & $40-59$ & 12 & CHD mortality \\
\hline Burke et al $2007^{29}$ & Western Australian Aboriginal cohort & 514 & Australia & 50.2 & $15-88$ & 11.6 & Incident CHD \\
\hline Camargo et al $1997^{30}$ & Physicians' Health Study & 22071 & USA & 100 & $40-84$ & 11 & Incident CHD \\
\hline \multirow{2}{*}{ Chiuve et al $2008^{31}$} & Nurses' Health Study & 71243 & USA & 0 & $34-59$ & 20 & Incident stroke \\
\hline & Health Professionals Follow-up Study & 43685 & USA & 100 & $40-75$ & 18 & Incident stroke \\
\hline Colditz et al $1985^{32}$ & Massachusetts cohort & 1184 & USA & 38 & $\geq 66$ & 4.75 & CHD mortality \\
\hline Cullen et al $1993^{33}$ & Brusselton, Western Australian cohort & 2171 & Australia & 50 & $\geq 40$ & 23 & CHD and CVD mortality \\
\hline \multirow{2}{*}{ Deev et al $1998^{34}$} & \multirow{2}{*}{$\begin{array}{l}\text { US-Russian Lipid Research Clinics } \\
\text { Prevalence Study }\end{array}$} & 4011 & USA & 46.6 & $40-69$ & 13 & \multirow{2}{*}{ CVD mortality } \\
\hline & & 4153 & Russia & 46.7 & $40-69$ & 13 & \\
\hline Diem et al $2003^{35}$ & Multinational Study of Vascular Disease in Diabetes & 287 & Switzerland & 56.4 & $\geq 35$ & 12.6 & CHD mortality \\
\hline Djousse et al $2002^{36}$ & Framingham Study & 9171 & USA & 42.2 & $\geq 50$ & 10 & Incident stroke \\
\hline Djousse et al $2009^{37}$ & Women's Health Study & 26399 & USA & 0 & $\geq 45$ & 12 & CVD mortality \\
\hline Doll et al $2005^{38}$ & British Physician Cohort & 12325 & UK & 100 & $48-78$ & 23 & CHD mortality \\
\hline Donahue et al $1986^{39}$ & Honolulu Heart Program & 8006 & USA & 100 & $45-69$ & 12 & Incident stroke \\
\hline Ebbert et al $2005^{40}$ & lowa Women's Health Study & 30518 & USA & 0 & $55-69$ & 14 & CHD mortality \\
\hline \multirow{2}{*}{ Ebrahim et al $2008^{41}$} & Women's Heart and Health Study & 2717 & UK & 0 & $60-79$ & 4.7 & \multirow{2}{*}{ Incident CHD } \\
\hline & Caerphilly Study & 1291 & UK & 100 & $47-67$ & 20 & \\
\hline Elkind et al $2006^{42}$ & Northern Manhattan Study & 3176 & USA & 37.2 & $\geq 40$ & 5.9 & Incident stroke \\
\hline Friedman et al $1986^{43}$ & Framingham Study & 4745 & USA & 44.4 & $30-59$ & 24 & CHD mortality \\
\hline Fuchs et al $1995^{44}$ & Nurses' Health Study & 85709 & USA & 0 & $34-59$ & 12 & CVD mortality \\
\hline Fuchs et al $2004^{45}$ & Atherosclerosis Risk in Communities Study & 14506 & USA & 43.3 & $45-64$ & 9.8 & Incident CHD \\
\hline Garfinkel et al $1988^{46}$ & American Cancer Society Prospective Study & 581321 & USA & 0 & 130 & 12 & CHD mortality \\
\hline Garg et al $1992^{47}$ & National Health and Nutrition Examination Study & 3718 & USA & 0 & $45-74$ & 13 & CHD mortality \\
\hline Gaziano et al $2000^{48}$ & Physicians' Health Study & 89299 & USA & 100 & $40-84$ & 5.5 & CVD and stroke mortality \\
\hline Gordon et al $1983^{49}$ & Framingham Study & 4625 & USA & 43.8 & $29-62$ & 22 & Incident CHD \\
\hline Gordon et al $1985^{50}$ & Albany Study & 1755 & USA & 100 & $38-55$ & 18 & Incident CHD \\
\hline Gronbaek et al $1995^{51}$ & Copenhagen City Heart Study & 13285 & Denmark & 45.5 & $30-79$ & 12 & CVD mortality \\
\hline Gun et al $2006^{52}$ & $\begin{array}{l}\text { Employees of Australian Institute of Petroleum } \\
\text { member companies }\end{array}$ & 16547 & Australia & 100 & NR & 20 & CHD mortality \\
\hline Hammar et al $1997^{53}$ & Swedish Twin Register & 1900 & Sweden & 67.4 & $30-74$ & NR & Incident CHD \\
\hline Hansagi et al $1995^{54}$ & Swedish Twin Register & 15077 & Sweden & 47 & $\geq 42$ & 20 & Stroke mortality \\
\hline Harriss et al $2007^{55}$ & Melbourne Collaborative Cohort Study & 38200 & Australia & 39.7 & $27-75$ & 11.4 & CHD and CVD mortality \\
\hline Hart et al $2008^{56}$ & Midspan Collaborative Cohort Study & 6000 & Scotland & 100 & $35-64$ & 35 & CHD and stroke mortality \\
\hline Hein et al $1996^{57}$ & Copenhagen Male Study & 2826 & Denmark & 100 & $53-74$ & 6 & Incident CHD \\
\hline Ikehara et al $2009^{58}$ & Japan Public Health Center-Based Prospective Study & 19356 & Japan & 100 & $40-69$ & 9.9 & Incident CHD and stroke \\
\hline Iso et al $1995^{59}$ & Rural Japanese cohorts & 2890 & Japan & 100 & $40-69$ & 10.5 & Incident CHD and stroke \\
\hline Jakovljevic et al $2004^{60}$ & Institute for Chronic Diseases and Gerontology & 286 & $\begin{array}{l}\text { Serbia and } \\
\text { Montenegro }\end{array}$ & 50.7 & $30-60$ & 20 & Stroke mortality \\
\hline Jamrozik et al $2000^{61}$ & Perth Community Stroke Study & 931 & Australia & 48 & $>18$ & 4 & CVD mortality \\
\hline Jousilahti et al $2000^{62}$ & Finnish Cohort & 14874 & Finland & 48.2 & $25-64$ & 12 & Incident stroke \\
\hline Kitamura et al $1998^{63}$ & Japanese Male Employees & 8476 & Japan & 100 & $40-59$ & 8.8 & Incident CHD \\
\hline Kittner et al $1983^{64}$ & Puerto Rico Heart Health Program & 9150 & Puerto Rico & 100 & $35-79$ & 12 & Incident CHD and CHD mortality \\
\hline Kivela et al $1989^{65}$ & Two Finnish cohorts from the Seven Countries Study & 1112 & Finland & 100 & $55-74$ & 10 & CVD mortality \\
\hline Kiyohara et al $1995^{66}$ & Hisayama Study & 1621 & Japan & 43.6 & $\geq 40$ & 26 & Incident stroke \\
\hline Klatsky et al $1990^{67}$ & \multirow{3}{*}{ Kaiser Permanente Medical Care Program Cohort } & 123840 & USA & 40.5 & $\langle 30 \rightarrow 70$ & 7 & CVD mortality \\
\hline Klatsky et al $1997^{68}$ & & 128934 & USA & 44 & $\langle 30 \rightarrow\rangle 0$ & NR & Incident CHD \\
\hline Klatsky et al $2002^{69}$ & & 128934 & USA & 44 & $\langle 30->70$ & 18 & Incident stroke \\
\hline Knoops et al $2004^{70}$ & Healthy Ageing: A Longitudinal Study in Europe & 2339 & $\begin{array}{l}11 \text { European } \\
\text { countries }\end{array}$ & 64.4 & $70-90$ & 10 & CHD and CVD mortality \\
\hline
\end{tabular}




\begin{tabular}{|c|c|c|c|c|c|c|c|}
\hline Study & Cohort designation & $\begin{array}{c}\text { No of } \\
\text { subjects }\end{array}$ & Country & Men (\%) & $\begin{array}{c}\text { Age } \\
\text { range } \\
\text { (years) }\end{array}$ & $\begin{array}{l}\text { Study } \\
\text { follow-up } \\
\text { (years) }\end{array}$ & Outcomes measured \\
\hline Kono et al $1986^{71}$ & Japanese Male Physician Cohort & 5135 & Japan & 100 & NR & 19 & CHD, CVD and stroke mortality \\
\hline Leppala et al $1999^{72}$ & $\begin{array}{c}\text { Alpha-Tocopherol, Beta-Carotene Cancer Prevention } \\
\text { cohort }\end{array}$ & 26556 & Finland & 100 & $50-69$ & 6.1 & Incident stroke \\
\hline Lin et al $2005^{73}$ & $\begin{array}{l}\text { Japan Collaborative Cohort Study for Evaluation } \\
\text { of Cancer Risk }\end{array}$ & 110792 & Japan & 41.9 & $40-79$ & 11 & CVD mortality \\
\hline Manttari et al $1997^{74}$ & Helsinki Heart Study & 1924 & Finland & 100 & $40-55$ & 5 & Incident CHD \\
\hline \multirow{2}{*}{$\begin{array}{l}\text { Marques-Vidal et al } \\
2004^{55}\end{array}$} & PRIME Study_France & 7352 & France & 100 & $50-59$ & 5 & \multirow{2}{*}{ Incident CHD } \\
\hline & PRIME Study—Northern Ireland & 2398 & Ireland & 100 & $50-59$ & 5 & \\
\hline Maskarinec et al $1998^{76}$ & Multiethnic cohort (Hawaii) & 27678 & USA & 50.1 & 130 & NR & CHD and stroke mortality \\
\hline Mukamal et al $2003^{77}$ & Health Professionals Follow-up Study & 38077 & USA & 100 & $40-75$ & 12 & Incident $\mathrm{CHD}$ and $\mathrm{CHD}$ mortality \\
\hline Mukamal et al $2005^{78}$ & \multirow{2}{*}{ Cardiovascular Health Study } & 4410 & USA & 36.1 & $\geq 65$ & 9.2 & Incident stroke \\
\hline Mukamal et al $2006^{79}$ & & 4410 & USA & 38.7 & $\geq 65$ & 9.2 & Incident CHD \\
\hline Murray et al $2002^{80}$ & Manitoba Health Cohort & 1154 & Canada & 50.2 & $18-64$ & 8 & Incident CHD \\
\hline Murray et al $2005^{81}$ & Lung Health Study & 3702 & Canada & 100 & $35-60$ & 14 & Incident CHD \\
\hline Pedersen et al $2008^{82}$ & Copenhagen City Heart Study & 11914 & Denmark & 44.3 & $\geq 20$ & 20 & CHD mortality \\
\hline Rehm et al $1997^{83}$ & National Health and Nutrition Examination Study & 6788 & USA & 43.6 & $40-75$ & 14.6 & Incident CHD and CHD mortality \\
\hline Renaud et al $1999^{84}$ & Cohort from Centre de Medecine Preventive & 36250 & France & 100 & $40-60$ & $12-18$ & CHD and CVD mortality \\
\hline Salonen et al $1983^{85}$ & Two counties of eastern Finland & 4063 & Finland & 100 & $30-59$ & 7 & Incident CHD \\
\hline Sankai et al $2000^{86}$ & Six Japanese communities & 12372 & Japan & 40.2 & $40-69$ & 9.4 & Incident stroke \\
\hline Scherr et al $1992^{87}$ & $\begin{array}{l}\text { Established populations for Epidemiologic Studies } \\
\text { of the Elderly }\end{array}$ & 6891 & USA & 36.9 & $>65$ & 5 & CVD mortality \\
\hline Shaper et al $1987^{88}$ & British Regional Heart Study & 6103 & UK & 100 & $40-59$ & 6.2 & Incident CHD \\
\hline Simons et al $1996^{89}$ & Dubbo Cohort of New South Wales & 2805 & Australia & 44.1 & $\geq 60$ & 6.4 & Incident CHD \\
\hline Solomon et al $2000^{90}$ & Nurses' Health Study & 121700 & USA & 0 & $30-55$ & NR & Incident CHD and CHD mortality \\
\hline Suh et al $1992^{91}$ & Multiple Risk Factor Intervention Trial & 11688 & USA & 100 & $35-57$ & 3.8 & CHD mortality \\
\hline Suhonen et al $1987^{92}$ & $\begin{array}{l}\text { Social Insurance Institution's Mobile Clinic Health } \\
\text { Survey }\end{array}$ & 4532 & Finland & 100 & $40-64$ & 5 & CHD mortality \\
\hline Thun et al $1997^{93}$ & Cancer Prevention Study II & 489626 & USA & 51.3 & 30-104 & 9 & CHD, CVD and stroke mortality \\
\hline Tolstrup et al $2006^{94}$ & Danish Cohort & 53500 & Denmark & 46.8 & $50-65$ & 5.7 & Incident CHD \\
\hline Trevisan et al $2001^{95}$ & Risk Factors and Life Expectancy Study & 8647 & Italy & 100 & $30-59$ & 7 & CHD and CVD mortality \\
\hline Truelsen et al $1998^{96}$ & Copenhagen City Heart Study & 13329 & Denmark & 45.5 & $45-84$ & 16 & Incident stroke \\
\hline Valmadrid et al $1999^{97}$ & $\begin{array}{c}\text { Wisconsin Epidemiologic Study of Diabetic } \\
\text { Retinopathy }\end{array}$ & 983 & USA & 45.2 & NR & 12.3 & CHD mortality \\
\hline Waskiewicz et al $2004^{98}$ & Pol-MONICA Programme & 5452 & Poland & 49.3 & $35-64$ & NR & CVD mortality \\
\hline Wellmann et al $2004^{99}$ & MONICA Augsburg Cohort & 2710 & Germany & 49.6 & $35-64$ & 10 & Incident CHD \\
\hline Wilkins $2002^{100}$ & National Population Health Survey & 6014 & Canada & 43.8 & $\geq 40$ & 4 & Incident CHD \\
\hline Woo et al $1990^{101}$ & Elderly Chinese Cohort & 427 & China & 40 & $\geq 60$ & 2.5 & Incident stroke \\
\hline Xu et al $2007^{102}$ & Husbands from Shanghai Women's Health Study & 64515 & China & 100 & $30-89$ & 4.6 & CHD and CVD mortality \\
\hline Yang et al $1999^{103}$ & South Bay Heart Watch Cohort & 1196 & USA & 89 & $\geq 45$ & 3.4 & Incident CHD \\
\hline Yuan et al $1997^{104}$ & Four communities in Shanghai & 18244 & China & 100 & $45-64$ & 6.7 & CHD and stroke mortality \\
\hline Zhang et al $2004^{105}$ & Northern and southern Chinese populations & 12352 & China & 100 & $35-59$ & 15.2 & Incident stroke \\
\hline
\end{tabular}

studies to determine the association between alcohol consumption and the risk of death from all causes.

Both reviewers independently extracted data from all studies fulfilling the inclusion criteria, and any disagreement was resolved by consensus. We extracted the data elements of cohort name, sample size, and population demographics (country, percentage male, mean age or age range). We also extracted information for key indicators of study quality in observational studies proposed by Egger et $\mathrm{al}^{10}$ and Laupacis et al. ${ }^{12}$ Specifically, we evaluated the effect on each outcome of the number of potential confounding variables and the number of years participants were followed.
Data synthesis and analysis

The relative risk was used as the common measure of association across studies. Hazard ratios and incidence density ratios were directly considered as relative risks. Where necessary, odds ratios were transformed into relative risks with this formula:

Relative risk $=$ odds ratio $/\left[\left(1-\mathrm{P}_{\mathrm{o}}\right)+\left(\mathrm{P}_{\mathrm{o}} \times\right.\right.$ odds ratio $\left.)\right]$, in which $\mathrm{P}_{\mathrm{o}}$ is the incidence of the outcome of interest in the non-exposed group. ${ }^{13}$

The standard error of the resulting converted relative risk was then determined with this formula: SElog $($ relative risk $)=$ SElog $($ odds ratio $) \times \log ($ relative risk) $/ \log$ (odds ratio). 


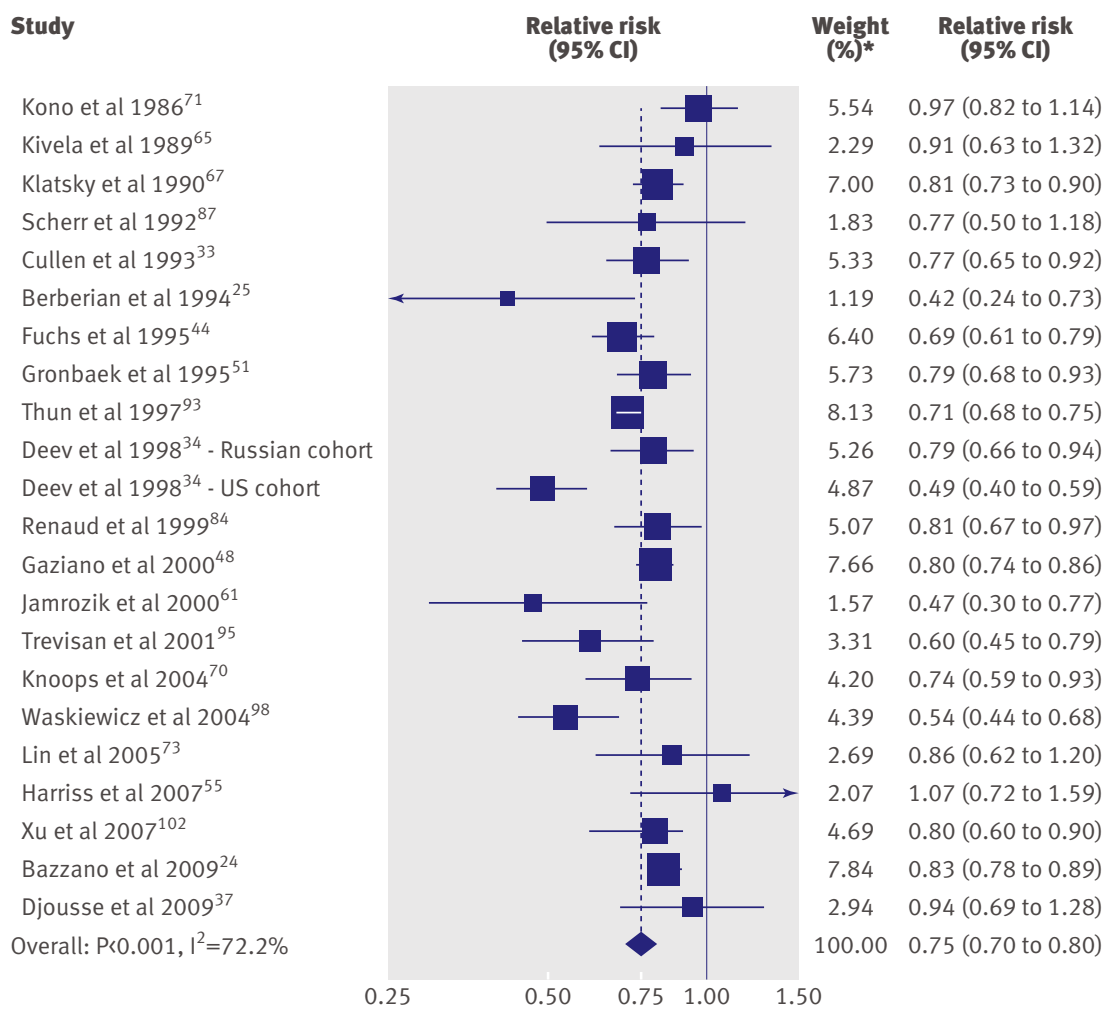

*Weight from random effects analysis

Fig 2 | Forest plot of mortality from cardiovascular disease associated with alcohol consumption analyses and stratified analyses were performed to assess the associations of selected study quality and clinical factors on cardiovascular risk, including number of confounding factors and duration of follow-up dichotomised at the median value. We also performed a sensitivity analysis excluding studies reporting only odds ratios. We conducted a cumulative meta-analysis of studies ordered chronologically to assess the sequential contributions of studies published over time. ${ }^{19}$ Finally, we assessed evidence of publication bias through visual inspection of funnel plots and Begg's rank correlation test for asymmetry. ${ }^{2021}$

\section{RESULTS}

\section{Identification of studies}

Our initial search yielded a total of 4235 unique citations (fig 1). After two rounds of reviews and searching citations of retained articles, we identified 131 studies as potentially relevant for analysis. We excluded studies of cardiovascular outcomes predefined as ineligible (such as chronic congestive heart failure or stable angina), non-atherothrombotic end points (such as arrhythmias), composite end points, or non-cardiovascular outcomes (such as cancer), and duplicate reports. This left 84 studies for our systematic review and meta-analysis. Table 1 provides details of the included studies. ${ }^{22-105}$ Of these 84 studies, 34 (40\%) reported on all-male cohorts, six $(7 \%)$ reported on women only, and $44(52 \%)$ included both men and women.

Because these transformations can underestimate the variance of the relative risks derived from the odds ratios, ${ }^{1415}$ we performed a sensitivity analysis that excluded four studies for which this transformation had been applied. All analyses were performed with Stata 10.0 (StataCorp, College Station TX, USA). The Stata "metan" command was used to pool the $\ln$ (relative risks) across studies according to the DerSimonian and Laird random effects model. ${ }^{16}$

In some studies, a single relative risk (or odds ratio) was not available for drinkers versus non-drinkers because the data were presented as only a doseresponse (that is, several alcohol consumption levels relative to non-drinkers). In these cases, we first pooled across levels of intake within the study using a random effects model to derive a single relative risk for drinkers versus non-drinkers. The resulting single, study-specific relative risk was then pooled with those of other studies.

To visually assess the relative risk estimates and corresponding 95\% confidence intervals across studies, we generated forest plots sorted by year of publication. Analyses were stratified by study quality criteria and by participant characteristics.

To assess heterogeneity of relative risks across studies, we inspected forest plots and calculated Q (significance level of $\mathrm{P} \leq 0.10$ ) and $\mathrm{I}^{2}$ statistics. ${ }^{17}{ }^{18}$ In the presence of heterogeneity, random effects models were used (rather than fixed effects models) to obtain pooled effect estimates across studies. Sensitivity

\section{Study quality}

We evaluated two primary features of study qualitythe number of years that participants were followed and adjustment for confounding. Duration of followup for study end points ranged from 2.5 to 35 years, with a mean follow-up of 11 years (standard deviation 6 years) (table 1). Of the included studies, $13(15 \%)$ had $\leq 5$ years of follow-up. Similarly, studies varied in the degree of confounder adjustment, ranging from none to 18 variables, with a mean of six (SD 4). Most studies (68) presented adjusted estimates, but eight reported only unadjusted estimates and another eight adjusted only for basic demographic information. Methods of adjustment, effect measure, and confounding variables used in each study are presented in the appendix tables 1-5 on bmj.com for each of our primary outcomes.

Primary analyses of cardiovascular disease mortality, coronary heart disease incidence and mortality, and stroke incidence and mortality

For cardiovascular disease mortality and both end points for coronary heart disease, alcohol consumption was associated with lower risk, with relative risks of about 0.75 (table 2). In general, relative risks derived from the more highly adjusted and from the less adjusted results were similar. Figures $2-4$ reveal little visual evidence of heterogeneity despite statistical evidence of heterogeneity $\left(\mathrm{P}<0.001, \mathrm{I}^{2}=72.2 \%\right)$, probably driven by the large number of participants $>1$ 


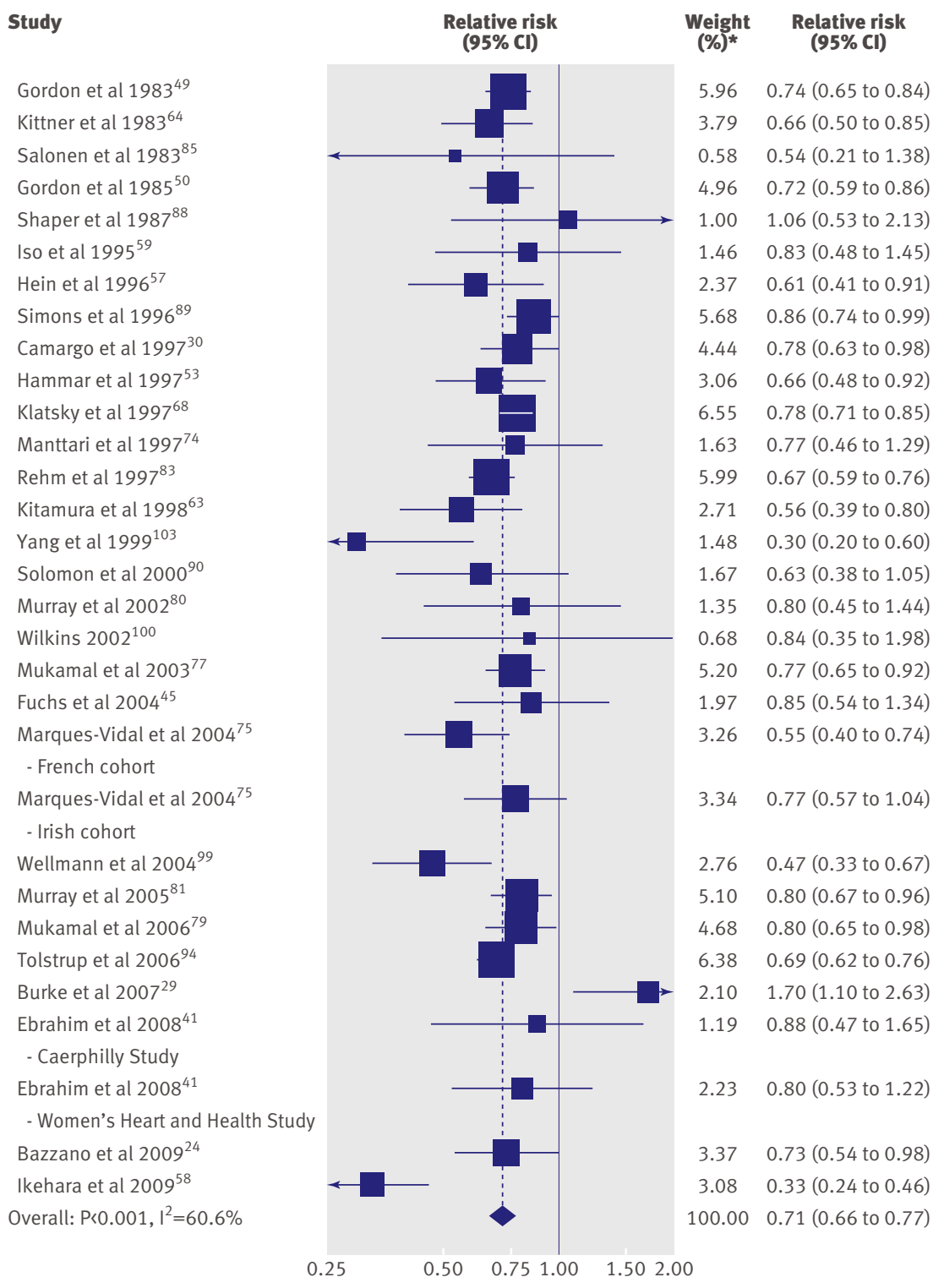

*Weight from random effects analysis

Fig 3 | Forest plot of incident coronary heart disease associated with alcohol consumption

million). All the point estimates were $<1.0$ in studies, except for one study for cardiovascular disease mortality and two studies for coronary heart disease incidence and mortality.

In contrast, the overall associations of alcohol intake with stroke incidence and mortality were close to null, both in minimally adjusted and more highly adjusted models (table 2, figs 5 and 6). However, this null association seemed to obscure nearly significant but opposite associations with subtypes of incident stroke. Among the 12 studies on incident haemorrhagic stroke, the pooled relative risk for current alcohol drinkers compared with non-drinkers was 1.14 (95\% confidence interval 0.97 to 1.34 ), whereas the eight studies on ischaemic stroke showed a moderate reduction in the pooled relative risk of 0.92 (0.85 to 1.00$)$. Alcohol use was not associated with stroke mortality, but few studies assessed the risk of mortality from haemorrhagic or ischaemic stroke separately. Furthermore, only two studies reported relative risks on stroke end points for former drinkers compared with nondrinkers.

\section{Analyses of dose response}

Analyses of the dose of alcohol consumed showed that $2.5-14.9 \mathrm{~g}$ alcohol (about $\leq 1$ drink) per day was protective for all five outcomes compared with no alcohol (table 2). For coronary heart disease outcomes, all levels of intake $>2.5 \mathrm{~g}$ /day had similar degrees of risk reduction. For cardiovascular disease mortality as well as stroke incidence and mortality, the dose-response relations were less clear and more consistent with $\mathrm{U}$ or J shaped curves, suggesting an increased risk among drinkers of greater amounts of alcohol. Specifically, those who consumed $>60 \mathrm{~g} /$ day were at a significantly increased risk of incident stroke compared with abstainers (relative risk 1.62 (1.32 to 1.98$)$ ).

\section{Sensitivity analyses}

In an analysis of differences in associations by sex, any amount of alcohol consumption relative to none was associated with greater reduction in cardiovascular disease mortality, stroke incidence, and stroke mortality for women than men. However, the association with stroke should be interpreted with caution, as the risk estimates for women are based on only three pooled studies. On the other hand, similar associations by sex were observed for coronary heart disease incidence and mortality (table 2).

Sensitivity analyses that were confined to only studies that controlled for the important confounders of smoking, age, and sex revealed generally similar results for all of the outcomes. Additional sensitivity analyses that account for the median number of confounding variables in the multivariable analyses of included studies revealed that those with fewer (less than the median) confounding variables generally reported slightly lower relative risk estimates. However, this pattern was inconsistent across the outcomes. Specifically, an increased risk of stroke mortality was observed for studies with limited adjustment for confounding. A similar trend was observed when considering the duration of follow-up. Using the pooled median number of years as the cut point, we found that studies with shorter follow-up reported a greater risk reduction for all outcomes except cardiovascular disease and coronary heart disease mortality (table 2).

Among those studies that used long term abstainers as the referent category, excluding former drinkers or evaluating them separately, the estimated association between drinking and both incidence and mortality estimates did not change substantively (table 2). Among studies that evaluated former drinkers separately, the risk of death (from cardiovascular disease and coronary heart disease) was significantly higher in former drinkers than in drinkers. However, former drinkers did not have an increased risk of incident cardiovascular events (coronary heart disease or stroke). 


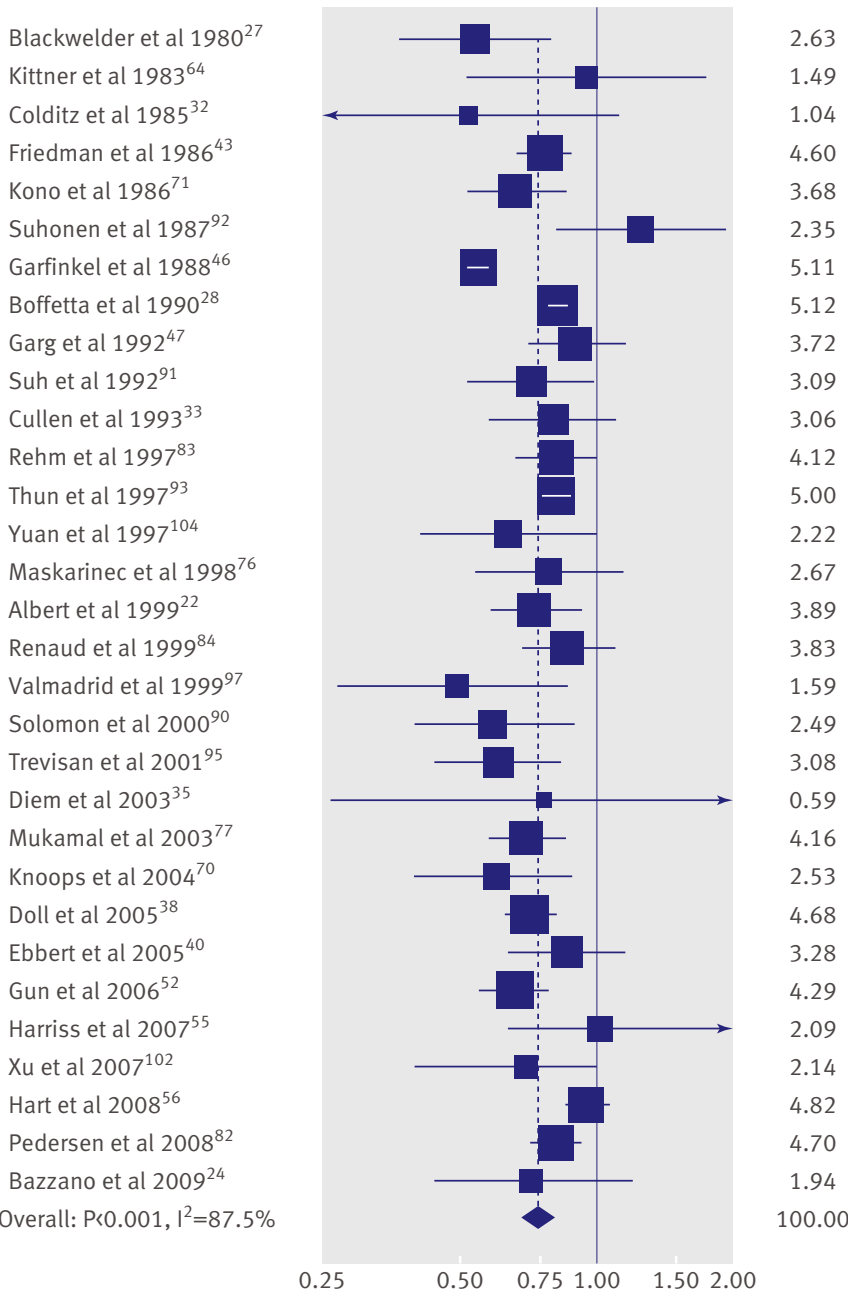

*Weight from random effects analysis

Fig 4 | Forest plot of mortality from coronary heart disease associated with alcohol consumption

Finally, a sensitivity analysis that excluded the few studies where only odds ratios instead of relative risks were presented had little effect on the results. In cumulative meta-analyses of cardiovascular disease and coronary heart disease outcomes (appendix figs 1-3 on bmj.com), there was little variation in the relative risk associated with alcohol consumption on cardiovascular disease mortality or incident coronary heart disease with addition of new studies after 1999; for coronary heart disease mortality, this plateau in incremental change from new studies occurred as early as 1992-3.

\section{Mortality from all causes}

Of the 84 studies addressing alcohol and cardiovascular disease events, 31 also examined the association of alcohol consumption with all cause mortality. The pooled estimates from these studies showed a lower risk of all cause mortality for drinkers compared with non-drinkers (relative risk 0.87 (0.83 to 0.92)) (fig 7). However, the association was J shaped, with the lowest risk for those consuming 2.5-14.9 g/day (relative risk 0.83 (0.80 to 0.86 ), 16 studies) and an elevated risk in those consuming $>60 \mathrm{~g} /$ day (relative risk 1.30 (1.22 to 1.38 ), 8 studies).

\section{Publication bias}

Visual inspection of the funnel plot for each outcome did not show asymmetry, an indication that significant publication bias was not likely. This was further confirmed by a non-significant Begg's test for each outcome (for cardiovascular disease mortality, $\mathrm{P}=0.40$; incident coronary heart disease, $\mathrm{P}=0.75$; coronary heart disease mortality, $\mathrm{P}=0.089$; incident stroke, $\mathrm{P}=0.33$; stroke mortality, $\mathrm{P}=0.59$; all cause mortality, $\mathrm{P}=0.26)$.

\section{DISCUSSION}

In this review of 84 studies of alcohol consumption and cardiovascular disease, alcohol consumption at 2.5$14.9 \mathrm{~g} /$ day (about $\leq 1 \mathrm{drink}$ a day) was consistently associated with a $14-25 \%$ reduction in the risk of all outcomes assessed compared with abstaining from alcohol. Such a reduction in risk is potentially of clinical importance, but consumption of larger amounts of alcohol was associated with higher risks for stroke incidence and mortality.

To our knowledge, this systematic review and metaanalysis is the most comprehensive to date. Although roughly similar estimates of lower risk were observed in previous meta-analyses of both coronary heart disease and stroke, ${ }^{1-8}$ our review extends the findings by assessing a broader array of relevant cardiovascular outcomes and adding several new important studies. Our review clarifies several discrepancies among prior reports. Corrao et al reported a J shaped relation between alcohol intake and coronary heart disease, ${ }^{2}$ whereas the review by Maclure described this relation as $\mathrm{L}$ shaped because he did not observe an increase in coronary heart disease risk associated with higher alcohol consumption. ${ }^{6}$ Our updated meta-analysis supports the latter association for coronary heart disease, with a 25-35\% risk reduction for light to moderate drinking ${ }^{106}$ that also is present with heavier drinking.

Our analysis of multiple cardiovascular outcomes also shows the complexities inherent in the study of alcohol consumption. Modest alcohol intake was associated with lower stroke incidence and mortality, but the risk increased substantially with heavier drinking (that is, a J shaped relation). Furthermore, the association of alcohol consumption is complex and differs by stroke subtype, with a slightly lower risk of ischaemic stroke but higher risk of haemorrhagic stroke. These differential associations probably reflect the known antithrombotic effects of alcohol. ${ }^{107}$ Alcohol consumption, particularly at high doses, also seems to have an adverse association with blood pressure that may account, in part, for the higher risk of haemorrhagic stroke associated with heavier drinking. ${ }^{108}$ Additionally, our analysis does not consider other known detrimental effects of high alcohol consumption. ${ }^{3}$ Therefore, our findings lend further support for limits on alcohol consumption. ${ }^{106} 109$ 
Table 2|Stratified analyses of pooled relative risks $(95 \% \mathrm{Cl})$ for cardiovascular and stroke outcomes (number of pooled studies in parentheses after each effect estimate)

\begin{tabular}{|c|c|c|c|c|c|}
\hline & \multirow{2}{*}{$\begin{array}{c}\text { Cardiovascular disease } \\
\text { mortality ( } \mathrm{n}=21 \text { studies, } \\
1184956 \text { subjects) }\end{array}$} & \multicolumn{2}{|c|}{ Coronary heart disease } & \multicolumn{2}{|c|}{ Stroke } \\
\hline & & $\begin{array}{l}\text { Incident (n=29 studies, } \\
549504 \text { subjects) }\end{array}$ & $\begin{array}{c}\text { Mortality ( } \mathrm{n}=31 \text { studies, } \\
1925106 \text { subjects) }\end{array}$ & $\begin{array}{l}\text { Incident ( } \mathrm{n}=17 \text { studies, } \\
458811 \text { subjects) }\end{array}$ & $\begin{array}{c}\text { Mortality (n=10 studies, } \\
723571 \text { subjects) }\end{array}$ \\
\hline \multicolumn{6}{|l|}{ Active drinkers $v$ non-drinkers: } \\
\hline Least adjusted models & $0.84(0.75$ to 0.95$)(11)$ & $0.73(0.65$ to 0.82$)(14)$ & $0.80(0.70$ to 0.91$)(10)$ & 1.01 (0.88 to 1.16$)(10)$ & $1.13(0.96$ to 1.32$)(3)$ \\
\hline Most adjusted models & $0.75(0.70$ to 0.80$)(21)$ & 0.71 (0.66 to 0.77$)(29)$ & $0.75(0.68$ to 0.81$)(31)$ & $0.98(0.91$ to 1.06$)(17)$ & $1.06(0.91$ to 1.23$)(10)$ \\
\hline Active drinkers $v$ lifetime abstainers & $0.82(0.78$ to 0.86$)(9)$ & $0.73(0.61$ to 0.88$)(9)$ & $0.75(0.66$ to 0.85$)(7)$ & $0.93(0.85$ to 1.02$)(7)$ & $1.29(1.09$ to 1.53$)(3)$ \\
\hline Former drinkers $v$ non-drinkers & 1.48 (1.23 to1.79) (6) & $1.10(0.91$ to 1.33$)(8)$ & $1.31(1.02$ to 1.68$)(6)$ & $0.87(0.72$ to 1.07$)(4)$ & Not reported (2) \\
\hline \multicolumn{6}{|l|}{ Alcohol intake (g/day) $v$ none: } \\
\hline$<2.5$ & $0.71(0.57$ to 0.89$)(7)$ & $0.96(0.86$ to 1.06$)(6)$ & $0.92(0.80$ to 1.06$)(6)$ & $0.81(0.74$ to 0.89$)(3)$ & $1.00(0.75$ to 1.34$)(3)$ \\
\hline $2.5-14.9$ & $0.77(0.71$ to 0.83$)(15)$ & $0.75(0.65$ to 0.88$)(9)$ & $0.79(0.73$ to 0.86$)(18)$ & $0.80(0.74$ to 0.87$)(3)$ & $0.86(0.75$ to 0.99$)(6)$ \\
\hline $15-29.9$ & 0.75 (0.70 to 0.80$)(13)$ & 0.66 (0.59 to 0.75$)(15)$ & $0.79(0.71$ to 0.88$)(15)$ & $0.92(0.82$ to 1.04$)(5)$ & $1.15(0.86$ to 1.54$)(6)$ \\
\hline $30-60$ & 0.85 (0.73 to 0.98$)(10)$ & $0.67(0.56$ to 0.79$)(9)$ & $0.77(0.72$ to 0.83$)(12)$ & $1.15(0.98$ to 1.35$)(4)$ & $1.10(0.85$ to 1.45$)(5)$ \\
\hline$>60$ & $0.99(0.84$ to 1.17$)(6)$ & $0.76(0.52$ to 1.09$)(9)$ & $0.75(0.63$ to 0.89$)(9)$ & $1.62(1.32$ to 1.98$)(4)$ & 1.44 (0.99 to 2.10$)(3)$ \\
\hline \multicolumn{6}{|l|}{ Sex: } \\
\hline Men & $0.80(0.73$ to 0.87$)(13)$ & 0.71 (0.66 to 0.77$)(25)$ & $0.77(0.72$ to 0.82$)(21)$ & $1.02(0.92$ to 1.13$)(11)$ & 1.07 (0.89 to 1.28$)(9)$ \\
\hline Women & $0.69(0.60$ to 0.78$)(9)$ & 0.71 (0.66 to 0.77$)(11)$ & $0.78(0.64$ to 0.94$)(10)$ & $0.87(0.75$ to 1.01$)(4)$ & 0.81 (0.67 to 0.98$)(3)$ \\
\hline \multicolumn{6}{|l|}{ Adjustment for confounding factors*: } \\
\hline Weak & $0.74(0.67$ to 0.82$)(10)$ & 0.69 (0.62 to 0.76$)(11)$ & $0.72(0.63$ to 0.83$)(15)$ & $0.99(0.86$ to 1.13$)(7)$ & $1.30(1.11$ to 1.52$)(5)$ \\
\hline Strong & $0.76(0.70$ to 0.83$)(11)$ & 0.72 (0.65 to 0.79$)(18)$ & $0.80(0.75$ to 0.86$)(16)$ & 0.99 (0.89 to 1.09$)(10)$ & $0.96(0.81$ to 1.14$)(5)$ \\
\hline \multicolumn{6}{|l|}{ Median follow-up time†: } \\
\hline Short & $0.76(0.71$ to 0.83$)(8)$ & 0.71 (0.65 to 0.79$)(14)$ & 0.75 (0.67 to 0.85$)(12)$ & $0.98(0.90$ to 1.07$)(9)$ & $1.01(0.82$ to 1.24$)(5)$ \\
\hline Long & $0.75(0.67$ to 0.84$)(13)$ & 0.72 (0.64 to 0.80$)(15)$ & 0.75 (0.67 to 0.84$)(19)$ & $1.00(0.88$ to 1.13$)(8)$ & $1.18(1.02$ to 1.37$)(5)$ \\
\hline
\end{tabular}

\section{Study}

Donahue et al $1986^{39}$ Woo et al $1990^{101}$

Kiyohara et al $1995^{66}$ Iso et al $1995^{59}$

Truelsen et al $1998^{96}$ Berger et al $1999^{26}$ Leppala et al $1999^{72}$ Jousilahti et al $2000^{62}$ Sankai et al $2000^{86}$ Djousse et al $2002^{36}$ Klatsky et al $2002^{69}$ Zhang et al $2004^{105}$ Mukamal et al $2005^{78}$ Elkind et al $2006^{42}$ Bazzano et al $2007^{23}$ Chuive et al $2008^{31}$

- Health Professionals Follow-up Study Chuive et al $2008^{31}$ - Nurses Health Study Ikehara et al $2009^{58}$ Overall: $\mathrm{P}=0.004, \mathrm{I}^{2}=53.1 \%$

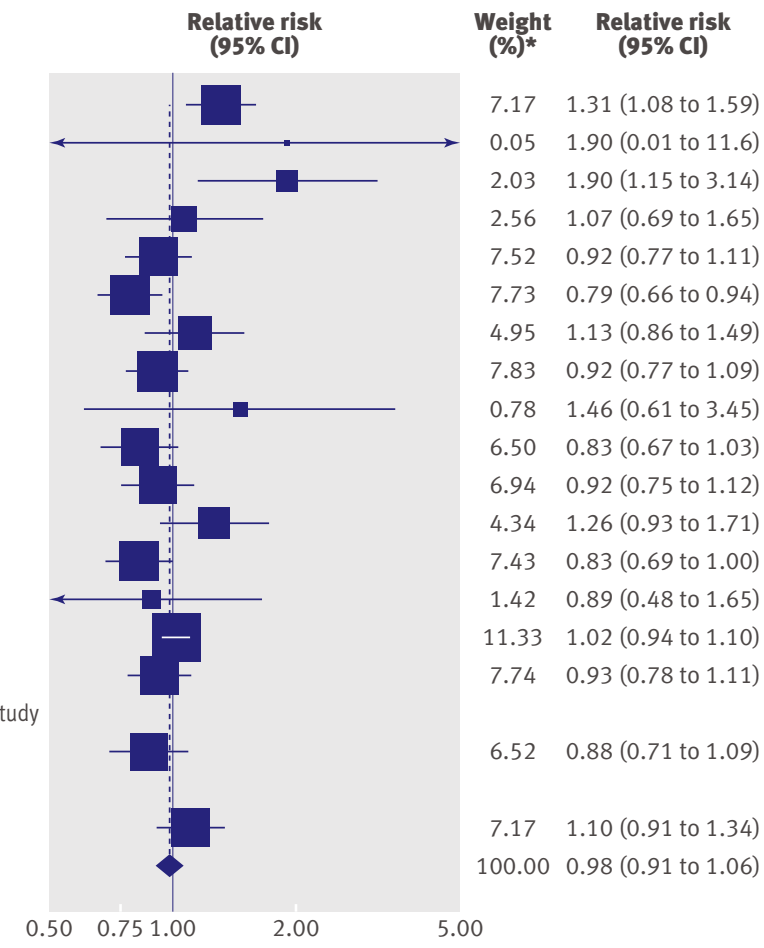

*Weight from random effects analysis

Fig 5 | Forest plot of incident stroke associated with alcohol consumption
Our review also highlights other important aspects of the relation between alcohol consumption and cardiovascular disease. Firstly, the lower risk of coronary heart disease associated with alcohol consumption was at least as strong for women as for men. Limited evidence suggests that the risk of stroke related to alcohol is lower for women than men, but this may only reflect lower alcohol intake among women. Secondly, inclusion of former drinkers did not seem to bias the association of alcohol consumption with cardiovascular disease. Thirdly, when studies were summarised chronologically, we found that the overall association between drinking and cardiovascular disease and coronary heart disease became apparent at least a decade ago, and ongoing studies have done little to revise the estimated associations.

\section{An argument for causation}

From the extensive body of literature summarised here, the association between alcohol consumption and decreased cardiovascular risk is not in question, as additional research has not changed this conclusion. Rather, the lingering question is whether this association is causal. Clearly, observational studies cannot establish causation. However, when the present results are coupled with those from our companion review paper summarising interventional mechanistic studies 


\section{Study}

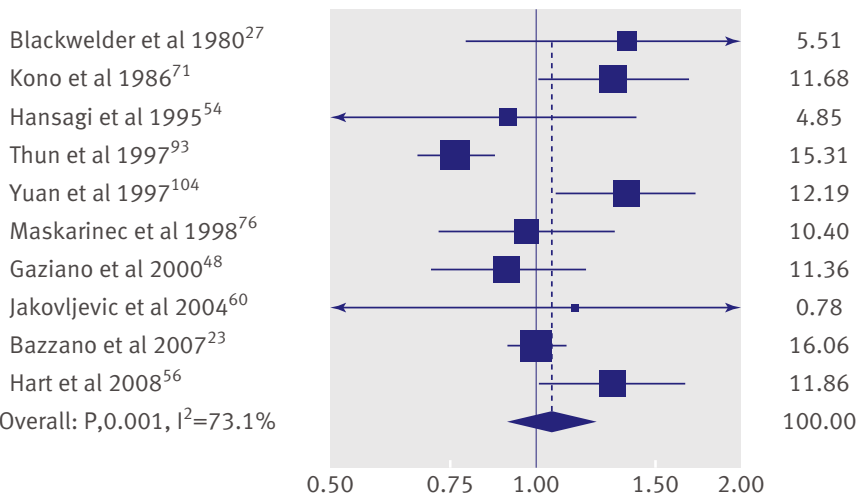

*Weight from random effects analysis

Fig 6 | Forest plot of mortality from stroke associated with alcohol consumption

\section{Relative risk} (95\% CI)

$1.36(0.79$ to 2.32$)$

1.30 (1.01 to 1.68$)$

$0.91(0.43$ to 1.40$)$

0.76 (0.67 to 0.87$)$

1.36 (1.07 to 1.72$)$

0.97 (0.72 to 1.31$)$

0.91 (0.70 to 1.19$)$

$1.14(0.21$ to 6.27$)$

$1.00(0.91$ to 1.11$)$

1.30 (1.01 to 1.66$)$

$1.06(0.91$ to 1.23$)$

\section{Study}

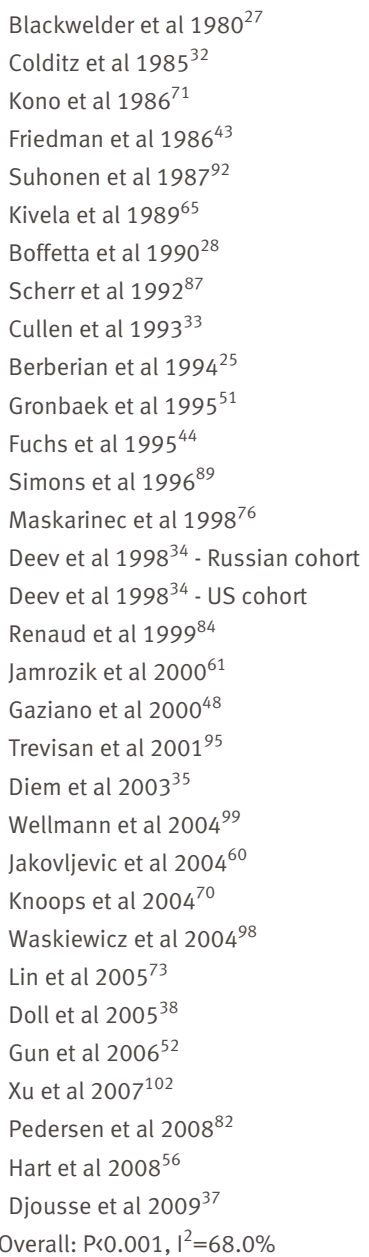

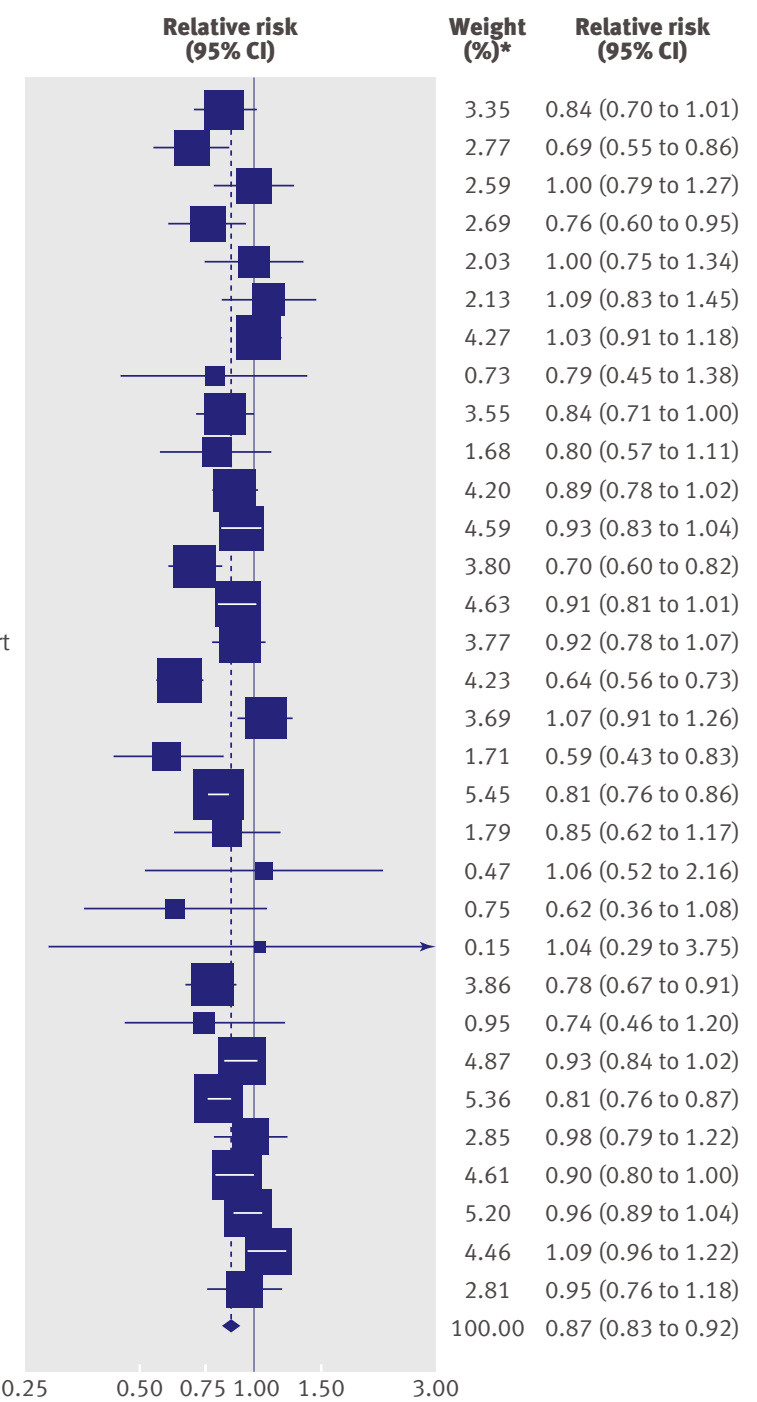

*Weight from random effects analysis focusing on biomarkers associated with cardiovascular disease,${ }^{110}$ the argument for causation becomes more compelling. Indeed, the mechanistic biomarker review shows biological plausibility for a causal association by showing favourable changes in pathophysiologically relevant molecules.

Therefore, we can now examine the argument for causation based on Hill's criteria. ${ }^{111}$ Beyond the biological plausibility argument discussed above, there is an appropriate temporal relation with alcohol use preventing cardiovascular disease. Secondly, we have observed a greater protective association with increasing dose, except that it seems to be offset somewhat by negative associations with the risk of haemorrhagic stroke. Thirdly, the protective association of alcohol has been consistently observed in diverse patient populations and in both women and men. Fourthly, the association is specific: moderate drinking (up to 1 drink or $12.5 \mathrm{~g}$ alcohol per day for women and 2 drinks or $25 \mathrm{~g}$ alcohol per day for men ${ }^{106}$ ) is associated with lower rates of cardiovascular disease but is not uniformly protective for other conditions, such as cancer. ${ }^{112}$ Lastly, the reduction in risk is notable even when controlling for known confounders (such as smoking, diet, and exercise). Any potential unmeasured confounder would need to be very strong to explain away the apparently protective association.

\section{Limitations of study}

The results of our meta-analysis should be interpreted in context of the limitations of available data. Firstly, the quality of individual studies varied, with some studies having limited follow-up and limited adjustment for potential confounding. With respect to study follow-up, it is possible that misclassification of alcohol consumption may increase with study length because of changes in drinking habits over time. It is also possible that potential biological effects of alcohol vary with time of exposure. However, arguing against both these possibilities, the analysis stratified by length of follow-up did not show different associations between alcohol intake and outcome for shorter follow-up times versus longer times.

Secondly, only a limited subset of studies provided specific risk estimates for different beverages. Although there is great interest in differences between beer, wine, and spirits, alcoholic drinks generally have similar effects on high density lipoprotein cholesterol, ${ }^{113}$ and it is likely that any particular benefit of wine is prone to confounding by diet and socioeconomic status. ${ }^{114115}$ None the less, this remains an interesting topic for further investigation.

Thirdly, we found only limited information on the relation between alcohol intake and mortality from subtypes of stroke, so this topic continues to be important for large observational cohort studies. Finally, we observed significant heterogeneity across studies for several of our pooled analyses. This may be due in great part to large study sample sizes, which can confer greater statistical power to heterogeneity tests, whereas the clinical relevance of this heterogeneity may be 


\section{WHAT IS ALREADY KNOWN ON THIS TOPIC:}

Systematic reviews have addressed the association of alcohol consumption with various cardiovascular outcomes

However, these reviews are somewhat out of date, and none has comprehensively studied a broad spectrum of relevant cardiovascular end points

\section{WHAT THIS STUDY ADDS}

This meta-analysis provides a summary of current knowledge regarding alcohol associations with six meaningful clinical end points-cardiovascular disease mortality, coronary heart disease incidence and mortality, stroke incidence and mortality, and all cause mortality

The results confirm the beneficial effects of moderate alcohol consumption and the need to elucidate the underlying pathophysiological mechanisms

quite modest. ${ }^{10}$ Visual inspection of our various forest plots and the relative consistency of pooled relative risks across clinical and methodological variables suggest that there is considerable consistency in the relative risk findings across studies and across strata.

\section{Implications}

Given the consistency observed in our findings and compelling mechanistic data pointing to causation in our companion review, additional observational studies will have limited value except to elucidate more precisely the association of alcohol and stroke. ${ }^{116}$ Rather, debate should centre now on how to integrate this evidence into clinical practice and public health messages. In the realm of clinical practice, the evidence could form a foundation for proposing counselling for selected patients to incorporate moderate amounts of alcohol into their diets to improve their coronary heart disease risk. However, such a clinical strategy requires formal evaluation in pragmatic clinical trials that assess the questions of optimal patient selection, compliance, risks, and benefits. The focus of such trials would shift from assessing the association between alcohol and disease outcomes to evaluating the receptivity of both physicians and patients to the recommended consumption of alcohol for therapeutic purposes and the extent to which it can be successfully and safely implemented. In support of implementation trials, our two papers show that alcohol consumption in moderation has reproducible and plausible effects on markers of coronary heart disease risk.

With respect to public health messages, there may now be an impetus to better communicate to the public that alcohol, in moderation, may have overall health benefits that outweigh the risks in selected subsets of patients. Again, any such strategy would need to be accompanied by rigorous study and oversight of impacts. One approach would be to undertake public health messaging pilot studies on well defined target populations (such as a workplace or in a small jurisdiction) to permit detailed evaluation of effects on measures such as knowledge, attitudes, self reported drinking behaviours, and perhaps, secondarily, health outcomes.
The debate on how to integrate this evidence into clinical practice and public health messages will require integration of all possible effects of alcoholfrom injury and violence to glucose metabolism and inflammation - and recognition that these effects may be distributed unequally across the population. For example, injury risk probably disproportionately affects younger individuals, whereas cardiovascular disease mainly affects older adults. Robust studies that examine multiple outcomes simultaneously are needed to identify those subsets of the population in which reduced cardiovascular risk might dominate against those for whom the risks of social and medical problems (including several cancers and injury ${ }^{11217}$ ) are too great. Despite the latter concerns, results of our secondary analysis of overall mortality (fig 5) support the notion that moderate alcohol consumption is associated with net benefit, at least in populations similar to those studied in the extant literature.

Our two systematic review papers summarise a surprisingly extensive body of literature on the relation between alcohol and cardiovascular disease. Our findings point to the need to define implications for clinical and public health practice. These reviews and the perspectives above provide a foundation for that dialogue.

Preliminary results from this manuscript were presented at the 32nd annual meeting of the Society of General Internal Medicine, Miami, Florida, 14 May 2009

Contributors: All authors conceived the study and developed the protocol. PER and SEB conducted the search, abstracted the data for the analysis, and performed the statistical analysis. PER, SEB, and WAG wrote the first draft of the manuscript. All authors had access to the data, critically reviewed the manuscript for important intellectual content, and approved the final version of the manuscript. WAG will act as guarantor for the paper.

Funding: This work was supported by a contracted operating grant from Program of Research Integrating Substance Use Information into Mainstream Healthcare (PRISM) funded by the Robert Wood Johnson Foundation, project No 58529, with cofunding by the Substance Abuse and Mental Health Services and the Administration Center for Substance Abuse Treatment. PER is supported by a Frederick Banting and Charles Best Canada Graduate Scholarship from the Canadian Institutes of Health Research. SEB is supported by a Postdoctoral Fellowship Award from the Alberta Heritage Foundation for Medical Research. WAG is supported by a Canada Research Chair in Health Services Research and by a Senior Health Scholar Award from the Alberta Heritage Foundation for Medical Research. The study was conducted independently of funding agencies. None of the funding agencies played an active role in the preparation, review, or editing of this manuscript.

Competing interests: All authors have completed the Unified Competing Interest form at www.icmje.org/coi_disclosure.pdf (available on request from the corresponding author) and declare: support from the Robert Wood Johnson Foundation, the Substance Abuse and Mental Health Services, and the Administration Center for Substance Abuse Treatment (as detailed above) for the submitted work, no financial relationships with any organisations that might have an interest in the submitted work in the previous three years, no other relationships or activities that could appea to have influenced the submitted work

Ethical approval: Not required.

Data sharing: Statistical code and datasets available from the corresponding author atwghali@ucalgary.ca

1 Cleophas TJ. Wine, beer and spirits and the risk of myocardial infarction: a systematic review. Biomed Pharmacother 1999;53:417-23.

2 Corrao G, Rubbiati L, Bagnardi V, Zambon A, Poikolainen K. Alcohol and coronary heart disease: a meta-analysis. Addiction 2000;95:1505-23 
3 Corrao G, Bagnardi V, Zambon A, La Vecchia C. A meta-analysis of alcohol consumption and the risk of 15 diseases. Prev Med 2004;38:613-9.

4 Di Castelnuovo A, Rotondo S, lacoviello L, Donati MB, De Gaetano G. Meta-analysis of wine and beer consumption in relation to vascular risk. Circulation 2002;105:2836-44.

5 Fillmore KM, Kerr WC, Stockwell T, Chikritzhs T, Bostrom A. Moderate alcohol use and reduced mortality risk: systematic error in prospective studies. Addiction Res Theory 2006;14:101-32.

6 Maclure M. Demonstration of deductive meta-analysis: ethanol intake and risk of myocardial infarction. Epidemiol Rev 1993;15:328-51.

7 Reynolds K, Lewis B, Nolen JD, Kinney GL, Sathya B, He J. Alcohol consumption and risk of stroke: a meta-analysis. JAMA 2003;289:579-88.

8 Rimm EB, Klatsky A, Grobbee D, Stampfer MJ. Review of moderate alcohol consumption and reduced risk of coronary heart disease: is the effect due to beer, wine, or spirits? BMJ 1996;312:731-6.

9 Stroup DF, Berlin JA, Morton SC, Olkin I, Williamson GD, Rennie D, et al. Meta-analysis of observational studies in epidemiology: a proposal for reporting. Meta-analysis of Observational Studies in Epidemiology (MOOSE) group. JAMA 2000;283:2008-12.

10 Egger M, Smith GD, Altman DG. Systematic reviews in health care: meta-analysis in context. BMJ Publishing Group, 2001.

11 Turner C. How much alcohol is in a "standard drink"? An analysis of 125 studies. Br J Addict 1990;85:1171-5.

12 Laupacis A, Wells G, Richardson S, Tugwell P. Users' guides to the medical literature: how to use an article about prognosis. EvidenceBased Medicine Working Group. JAMA 1994;272:234-7.

13 Zhang J, Yu KF. What's the relative risk? A method of correcting the odds ratio in cohort studies of common outcomes. JAMA 1998;280:1690-1.

14 Greenland S. Model-based estimation of relative risks and other epidemiologic measures in studies of common outcomes and in case-control studies. Am J Epidemiol 2004;160:301-5.

15 McNutt LA, Wu C, Xue X, Hafner JP. Estimating the relative risk in cohort studies and clinical trials of common outcomes. Am J Epidemiol 2003;157:940-3.

16 DerSimonian R, Laird N. Meta-analysis in clinical trials. Control Clin Trials 1986;7:177-88.

17 Higgins JP, Thompson SG. Quantifying heterogeneity in a metaanalysis. Stat Med 2002;21:1539-58.

18 Higgins JP, Thompson SG, Deeks JJ, Altman DG. Measuring inconsistency in meta-analyses. BMJ 2003;327:557-60.

19 Muellerleile P, Mullen B. Sufficiency and stability of evidence for public health interventions using cumulative meta-analysis. Am J Public Health 2006;96:515-22.

20 Egger M, Davey Smith G, Schneider M, Minder C. Bias in metaanalysis detected by a simple, graphical test. $B M$ J 1997;315:629-34.

21 Begg CB, Mazumdar M. Operating characteristics of a rank correlation test for publication bias. Biometrics 1994;50:1088-101.

22 Albert CM, Manson JE, Cook NR, Ajani UA, Gaziano JM, Hennekens $\mathrm{CH}$. Moderate alcohol consumption and the risk of sudden cardiac death among US male physicians. Circulation 1999;100:944-50.

23 Bazzano LA, Gu D, Reynolds K, Wu X, Chen CS, Duan X, et al. Alcoho consumption and risk for stroke among Chinese men. Ann Neurol 2007;62:569-78.

24 Bazzano LA, Gu D, Reynolds K, Chen J, Wu X, Chen CS, et al. Alcohol consumption and risk of coronary heart disease among Chinese men. Int J Cardiol 2009;135:78-85.

25 Berberian KM, van Duijn CM, Hoes AW, Valkenburg HA, Hofman A. Alcohol and mortality. Results from the EPOZ (Epidemiologic Study of Cardiovascular Risk Indicators) follow-up study. Eur J Epidemiol 1994;10:587-93.

26 Berger K, Ajani UA, Kase CS, Gaziano JM, Buring JE, Glynn RJ, et al. Light-to-moderate alcohol consumption and risk of stroke among US male physicians. N Engl J Med 1999;341:1557-64.

27 Blackwelder WC, Yano K, Rhoads GG, Kagan A, Gordon T, Palesch Y. Alcohol and mortality: the Honolulu Heart Study. Am J Med 1980;68:164-9.

28 Boffetta P, Garfinkel L. Alcohol drinking and mortality among men enrolled in an American Cancer Society prospective study. Epidemiology 1990;1:342-8.

29 Burke V, Lee AH, Hunter E, Spargo R, Smith R, Beilin LJ, et al. Alcohol intake and incidence of coronary disease in Australian aborigines. Alcohol 2007;42:119-24.

30 Camargo CA, Hennekens CH, Gaziano JM, Glynn RJ, Manson JE, Stampfer MJ. Prospective study of moderate alcohol consumption and mortality in US male physicians. Arch Intern Med 1997;157:79-85.

31 Chiuve SE, Rexrode KM, Spiegelman D, Logroscino G, Manson JE, Rimm EB. Primary prevention of stroke by healthy lifestyle. Circulation 2008;118:947-54.
32 Colditz GA, Branch LG, Lipnick RJ, Willett WC, Rosner B, Posner B, et al. Moderate alcohol and decreased cardiovascular mortality in an elderly cohort. Am Heart / 1985;109:886-9.

33 Cullen KJ, Knuiman MW, Ward NJ. Alcohol and mortality in Busselton, Western Australia. Am J Epidemiol 1993;137:242-8.

34 Deev A, Shestov D, Abernathy J, Kapustina A, Muhina N, Irving S. Association of alcohol consumption to morality in middle-aged US and Russian men and women. Ann Epidemiol 1998;8:147-53.

35 Diem P, Deplazes M, Fajfr R, Bearth A, Muller B, Christ ER, et al. Effects of alcohol consumption on mortality in patients with type 2 diabetes mellitus. Diabetologia 2003;46:1581-5.

36 Djousse L, Ellison RC, Beiser A, Scaramucci A, D’Agostino RB, Wolf PA. Alcohol consumption and risk of ischemic stroke: the Framingham Study. Stroke 2002;33:907-12.

37 Djousse L, Lee IM, Buring JE, Gaziano JM. Alcohol consumption and risk of cardiovascular disease and death in women: potential mediating mechanisms. Circulation 2009;120:237-44.

38 Doll R, Peto R, Boreham I, Sutherland I. Mortality in relation to alcohol consumption: a prospective study among male British doctors. Int J Epidemiol 2005;34:199-204

39 Donahue RP, Abbott RD, Reed DM, Yano K. Alcohol and hemorrhagic stroke. The Honolulu Heart Program. JAMA 1986;255:2311-4.

40 Ebbert JO, Janney CA, Sellers TA, Folsom AR, Cerhan JR. The association of alcohol consumption with coronary heart disease mortality and cancer incidence varies by smoking history. J Gen Intern Med 2005;20:14-20

41 Ebrahim S, Lawlor DA, Shlomo YB, Timpson N, Harbord R, Christensen $\mathrm{M}$, et al. Alcohol dehydrogenase type 1C (ADH1C) variants, alcohol consumption traits, HDL-cholesterol and risk of coronary heart disease in women and men: British Women's Heart and Health Study and Caerphilly cohorts. Atherosclerosis 2008;196:871-8.

42 Elkind MS, Sciacca R, Boden-Albala B, Rundek T, Paik MC, Sacco RL. Moderate alcohol consumption reduces risk of ischemic stroke: the Northern Manhattan Study. Stroke 2006;37:13-9.

43 Friedman LA, Kimball AW. Coronary heart disease mortality and alcohol consumption in Framingham. Am J Epidemiol 1986;124:481-9.

44 Fuchs CS, Stampfer MJ, Colditz GA, Giovannucci EL, Manson JE, Kawachi I, et al. Alcohol consumption and mortality among women. N Engl/ Med 1995:332:1245-50.

45 Fuchs FD, Chambless LE, Folsom AR, Eigenbrodt ML, Duncan BB, Gilbert A, et al. Association between alcoholic beverage consumption and incidence of coronary heart disease in whites and blacks: the Atherosclerosis Risk in Communities Study. Am J Epidemiol 2004;160:466-74.

46 Garfinkel L, Boffetta P, Stellman SD. Alcohol and breast cancer: a cohort study. Prev Med 1988;17:686-93.

47 Garg R, Wagener DK, Madans JH. Alcohol consumption and risk of ischemic heart disease in women. Arch Intern Med 1993;153:1211-6.

48 Gaziano JM, Gaziano TA, Glynn RJ, Sesso HD, Ajani UA, Stampfer M], et al. Light-to-moderate alcohol consumption and mortality in the Physicians' Health Study enrollment cohort. J Am Coll Cardiol 2000;35:96-105.

49 Gordon T, Kannel WB. Drinking habits and cardiovascular disease: the Framingham Study. Am Heart J 1983;105:667-73.

50 Gordon T, Doyle JT. Drinking and coronary heart disease: the Albany Study. Am Heart J 1985;110:331-4.

51 Gronbaek M, Deis A, Sorensen TI, Becker U, Schnohr P, Jensen G. Mortality associated with moderate intakes of wine, beer, or spirits. BMJ 1995;310:1165-9.

52 Gun RT, Pratt N, Ryan P, Gordon I, Roder D. Tobacco and alcoholrelated mortality in men: estimates from the Australian cohort of petroleum industry workers. Aust N Z J Public Health 2006;30:318-24.

53 Hammar N, Romelsjo A, Alfredsson L. Alcohol consumption, drinking pattern and acute myocardial infarction. A case referent study based on the Swedish Twin Register. J Intern Med 1997;241:125-31.

54 Hansagi H, Romelsjo A, Gerhardsson de Verdier M, Andreasson S, Leifman A. Alcohol consumption and stroke mortality. 20-year followup of 15,077 men and women. Stroke 1995;26:1768-73.

55 Harriss LR, English DR, Hopper JL, Powles J, Simpson JA, O’Dea K, et al. Alcohol consumption and cardiovascular mortality accounting for possible misclassification of intake: 11-year follow-up of the Melbourne Collaborative Cohort Study. Addiction 2007;102:1574-85

56 Hart CL, Smith GD. Alcohol consumption and mortality and hospital admissions in men from the Midspan Collaborative cohort study. Addiction 2008;103:1979-86.

57 Hein HO, Suadicani P, Gyntelberg F. Alcohol consumption, serum low density lipoprotein cholesterol concentration, and risk of ischaemic heart disease: six year follow up in the Copenhagen male study. BMJ 1996;312:736-41. 
58 Ikehara S, Iso H, Yamagishi K, Yamamoto S, Inoue M, Tsugane S, et al. Alcohol consumption, social support, and risk of stroke and coronary heart disease among Japanese men: the JPHC Study. Alcohol Clin Exp Res 2009;33:1025-32.

59 Iso H, Kitamura A, Shimamoto T, Sankai T, Naito Y, Sato S, et al. Alcohol intake and the risk of cardiovascular disease in middle-aged Japanese men. Stroke 1995;26:767-73.

60 Jakovljevic B, Stojanov V, Paunovic K, Belojevic G, Milic N. Alcohol consumption and mortality in Serbia: twenty-year follow-up study. Croat Med J 2004;45:764-8.

61 Jamrozik K, Broadhurst RJ, Forbes S, Hankey GJ, Anderson CS. Predictors of death and vascular events in the elderly: the Perth Community Stroke Study. Stroke 2000;31:863-8.

62 Jousilahti P, Rastenyte D, Tuomilehto J. Serum gamma-glutamyl transferase, self-reported alcohol drinking, and the risk of stroke. Stroke 2000;31:1851-5.

63 Kitamura A, Iso H, Sankai T, Naito Y, Sato S, Kiyama M, et al. Alcohol intake and premature coronary heart disease in urban Japanese men. Am J Epidemiol 1998;147:59-65.

64 Kittner SJ, Garcia-Palmieri MR, Costas R Jr, Cruz-Vidal M, Abbott RD, Havlik RJ. Alcohol and coronary heart disease in Puerto Rico. Am J Epidemiol 1983;117:538-50.

65 Kivela SL, Nissinen A, Ketola A, Punsar S, Puska P, Karvonen M. Alcohol consumption and mortality in aging or aged Finnish men.J Clin Epidemiol 1989;42:61-8.

66 Kiyohara Y, Kato I, Iwamoto H, Nakayama K, Fujishima M. The impact of alcohol and hypertension on stroke incidence in a general Japanese population. The Hisayama Study. Stroke 1995;26:368-72.

67 Klatsky AL, Armstrong MA, Friedman GD. Risk of cardiovascular mortality in alcohol drinkers, ex-drinkers and nondrinkers. Am J Cardiol 1990;66:1237-42.

68 Klatsky AL, Armstrong MA, Friedman GD. Red wine, white wine, liquor, beer, and risk for coronary artery disease hospitalization. $A m$ Cardiol 1997;80:416-20.

69 Klatsky AL, Armstrong MA, Friedman GD, Sidney S. Alcohol drinking and risk of hemorrhagic stroke. Neuroepidemiology 2002;21:115-22.

70 Knoops KT, de Groot LC, Kromhout D, Perrin AE, Moreiras-Varela O, Menotti A, et al. Mediterranean diet, lifestyle factors, and 10-year mortality in elderly European men and women: the HALE project. IAMA 2004;292:1433-9.

71 Kono S, Ikeda M, Tokudome S, Nishizumi M, Kuratsune M. Alcohol and mortality: a cohort study of male Japanese physicians. Int J Epidemiol 1986;15:527-32.

72 Leppala JM, Paunio M, Virtamo J, Fogelholm R, Albanes D, Taylor PR, et al. Alcohol consumption and stroke incidence in male smokers. Circulation 1999;100:1209-14.

73 Lin Y, Kikuchi S, Tamakoshi A, Wakai K, Kawamura T, Iso H, et al. Alcohol consumption and mortality among middle-aged and elderly Japanese men and women. Ann Epidemiol 2005;15:590-7.

74 Manttari M, Tenkanen L, Alikoski T, Manninen V. Alcohol and coronary heart disease: the roles of HDL-cholesterol and smoking. $J$ Intern Med 1997;241:157-63.

75 Marques-Vidal P, Montaye M, Arveiler D, Evans A, Bingham A, Ruidavets JB, et al. Alcohol consumption and cardiovascular disease: differential effects in France and Northern Ireland. The PRIME study. Eur J Cardiovasc Prev Rehabil 2004;11:336-43.

76 Maskarinec G, Meng L, Kolonel LN. Alcohol intake, body weight, and mortality in a multiethnic prospective cohort. Epidemiology 1998;9:654-61.

77 Mukamal KJ, Conigrave KM, Mittleman MA, Camargo CA Jr, Stampfer MJ, Willett WC, et al. Roles of drinking pattern and type of alcohol consumed in coronary heart disease in men. N Engl J Med 2003;348:109-18

78 Mukamal KJ, Chung H, Jenny NS, Kuller LH, Longstreth WT Jr, Mittleman MA, et al. Alcohol use and risk of ischemic stroke among older adults: the cardiovascular health study. Stroke 2005;36:1830-4.

79 Mukamal KJ, Chung $\mathrm{H}$, Jenny NS, Kuller LH, Longstreth WT Jr, Mittleman MA, et al. Alcohol consumption and risk of coronary hear disease in older adults: the Cardiovascular Health Study. J Am Geriat Soc 2006;54:30-7.

80 Murray RP, Connett JE, Tyas SL, Bond R, Ekuma O, Silversides CK, et al. Alcohol volume, drinking pattern, and cardiovascular disease morbidity and mortality: is there a U-shaped function? Am J Epidemiol 2002;155:242-8.

81 Murray RP, Connett JE, Makela P, Rehm J. Difficulty in demonstrating a risk from drinking pattern in fourteen years of coronary heart disease morbidity and mortality: the Lung Health Study. Addict Behav 2005;30:875-87

82 Pedersen JO, Heitmann BL, Schnohr P, Gronbaek M. The combined influence of leisure-time physical activity and weekly alcohol intake on fatal ischaemic heart disease and all-cause mortality. Eur Heart 2008;29:204-12.
83 Rehm JT, Bondy SJ, Sempos CT, Vuong CV. Alcohol consumption and coronary heart disease morbidity and mortality. Am J Epidemiol 1997;146:495-501.

84 Renaud SC, Gueguen R, Siest G, Salamon R. Wine, beer, and mortality in middle-aged men from eastern France. Arch Intern Med 1999;159:1865-70.

85 Salonen JT, Puska P, Nissinen A. Intake of spirits and beer and risk of myocardial infarction and death-a longitudinal study in Eastern Finland. J Chronic Dis 1983;36:533-43.

86 Sankai T, Iso H, Shimamoto T, Kitamura A, Naito Y, Sato S, et al. Prospective study on alcohol intake and risk of subarachnoid hemorrhage among Japanese men and women. Alcohol Clin Exp Res 2000;24:386-9.

87 Scherr PA, LaCroix AZ, Wallace RB, Berkman L, Curb JD, Cornoni-Huntley J, et al. Light to moderate alcohol consumption and mortality in the elderly. J Am Geriatr Soc 1992;40:651-7.

88 Shaper AG, Phillips AN, Pocock SJ, Walker M. Alcohol and ischaemic heart disease in middle aged British men. BMJ 1987;294:733-7.

89 Simons LA, McCallum J, Friedlander Y, Simons J. Alcohol intake and survival in the elderly: a 77 month follow-up in the Dubbo study. Aust N ZJ Med 1996;26:662-70.

90 Solomon CG, Hu FB, Stampfer MJ, Colditz GA, Speizer FE, Rimm EB, et al. Moderate alcohol consumption and risk of coronary heart disease among women with type 2 diabetes mellitus. Circulation 2000;102:494-9.

91 Suh I, Shaten BJ, Cutler JA, Kuller LH. Alcohol use and mortality from coronary heart disease: the role of high-density lipoprotein cholesterol. The Multiple Risk Factor Intervention Trial Research Group. Ann Intern Med 1992;116:881-7.

92 Suhonen O, Aromaa A, Reunanen A, Knekt P. Alcohol consumption and sudden coronary death in middle-aged Finnish men. Acta Med Scand 1987;221:335-41.

93 Thun MJ, Peto R, Lopez AD, Monaco JH, Henley SJ, Heath CW Jr, et al. Alcohol consumption and mortality among middle-aged and elderly US adults. N Engl J Med 1997;337:1705-14.

94 Tolstrup J, Jensen MK, Tjonneland A, Overvad K, Mukamal KJ, Gronbaek M. Prospective study of alcohol drinking patterns and coronary heart disease in women and men. BMJ 2006;332:1244-8.

95 Trevisan M, Schisterman E, Mennotti A, Farchi G, Conti S. Drinking pattern and mortality: the Italian Risk Factor and Life Expectancy pooling project. Ann Epidemiol 2001;11:312-9.

96 Truelsen T, Gronbaek M, Schnohr P, Boysen G. Intake of beer, wine, and spirits and risk of stroke: the Copenhagen city heart study. Stroke 1998;29:2467-72.

97 Valmadrid CT, Klein R, Moss SE, Klein BE, Cruickshanks KJ. Alcohol intake and the risk of coronary heart disease mortality in persons with older-onset diabetes mellitus. JAMA 1999;282:239-46.

98 Waskiewicz A, Sygnowska E, Drygas W. Relationship between alcohol consumption and cardiovascular mortality-the Warsaw PolMONICA Project. Kardiol Pol 2004;60:552-62.

99 Wellmann J, Heidrich J, Berger K, Doring A, Heuschmann PU, Keil U. Changes in alcohol intake and risk of coronary heart disease and allcause mortality in the MONICA/KORA-Augsburg cohort 1987-97. Eur I Cardiovasc Prev Rehabil 2004;11:48-55.

100 Wilkins K. Moderate alcohol consumption and heart disease. Health Rep 2002;14:9-24.

101 Woo J, Lau EM. Risk factors predisposing to stroke in an elderly Chinese population-a longitudinal study. Neuroepidemiology 1990;9:131-4.

102 Xu WH, Zhang XL, Gao YT, Xiang YB, Gao LF, Zheng W, et al. Joint effect of cigarette smoking and alcohol consumption on mortality. Prev Med 2007;45:313-9.

103 Yang T, Doherty TM, Wong ND, Detrano RC. Alcohol consumption, coronary calcium, and coronary heart disease events. Am J Cardiol 1999;84:802-6.

104 Yuan JM, Ross RK, Gao YT, Henderson BE, Yu MC. Follow up study of moderate alcohol intake and mortality among middle aged men in Shanghai, China. BMJ 1997;314:18-23.

105 Zhang LF, Zhao LC, Zhou BF, Yang J, LiY, Wu YF. Alcohol consumption and incidence of ischemic stroke in male Chinese. Zhonghua Liu Xing Bing Xue Za Zhi 2004;25:954-7.

106 US Government. Alcoholic beverages: dietary guidelines for Americans 2005. US Government Printing Office, 2005.

107 Rubin R, Rand ML. Alcohol and platelet function. Alcohol Clin Exp Res 1994;18:105-10.

108 Mukamal KJ, Ascherio A, Mittleman MA, Conigrave KM, Camargo CA Jr, Kawachi I, et al. Alcohol and risk for ischemic stroke in men: the role of drinking patterns and usual beverage. Ann Intern Med 2005;142:11-9.

109 National Institute on Alcohol Abuse and Alcoholism. Rethinking drinking: alcohol and your health. What's low risk drinking? 2010. http://rethinkingdrinking.niaaa.nih.gov/ IsYourDrinkingPatternRisky/WhatsLowRiskDrinking.asp. 
110 Brien SE, Ronksley PE, Turner BJ, Mukamal KJ, Ghali WA. Effect of alcohol consumption on biological markers associated with risk of coronary heart disease: systematic review and meta-analysis of interventional studies. BMJ 2011;342:d636.

111 Hill AB. The environment and disease: association or causation? Proc R Soc Med 1965;58:295-300.

112 McPherson K. Moderate alcohol consumption and cancer. Ann Epidemiol 2007;17:S46-8.

113 Rimm EB, Williams P, Fosher K, Criqui M, Stampfer MJ. Moderate alcohol intake and lower risk of coronary heart disease: metaanalysis of effects on lipids and haemostatic factors. BMJ 1999;319:1523-8
114 Johansen D, Friis K, Skovenborg E, Gronbaek M. Food buying habits of people who buy wine or beer: cross sectional study. BMJ 2006;332:519-22.

115 Tjonneland A, Gronbaek M, Stripp C, Overvad K. Wine intake and diet in a random sample of 48763 Danish men and women. Am J Clin Nutr 1999;69:49-54.

116 Klatsky AL. Alcohol and cardiovascular mortality: common sense and scientific truth. J Am Coll Cardiol 2010;55:1336-8.

117 Cherpitel CJ. Alcohol, injury, and risk-taking behavior: data from a national sample. Alcohol Clin Exp Res 1993;17:762-6.

Accepted: 12 December 2010 